\title{
A Ray of Hope for Tender Joints: Vitamin D and Rheumatoid Arthritis
}

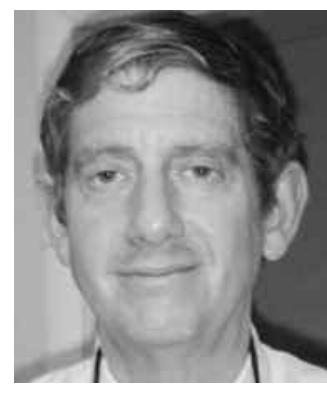

A growing body of evidence is clarifying the role of vitamin $\mathrm{D}$ in the pathogenesis of several autoimmune rheumatic diseases, including rheumatoid arthritis (RA), systemic lupus erythematosus (SLE), polymyositis/dermatomyositis, and Beçhet's disease ${ }^{1}$. This should not come as a surprise to anyone, since vitamin D is not truly a vitamin at all, but a steroid hormone that can act through receptors found on cells in multiple organ systems, including the immune sys$t^{2}{ }^{2}$. In vitamin D receptor knockout mice, $\mathrm{T}$ cells that lack these receptors upregulate the immune response through enhanced proinflammatory cytokine release ${ }^{3}$.

Cutolo has succinctly outlined changes in immunocyte function that vitamin D induces in vitro and in animal models that are relevant to the pathogenesis of autoimmune disease $^{4}$. There is a vitamin D-induced arrest of differentiation and maturation of populations of dendritic cells, T cells, and $\mathrm{B}$ cells, with an increase in the production of interleukin 10 (IL-10) and a reduction of IL-12, retarding dendritic cell development and inducing apoptosis. Levels of the proinflammatory cytokine IL-17 are diminished. Fewer plasma and post-switch memory B cells are produced. There are augmented numbers of tolerogenic dendritic cells and natural killer $\mathrm{T}$ cells that downregulate experimentally induced autoimmunity.

$\mathrm{T}$ cells are derived from precursor stem cells in the bone marrow, and mature in the thymus ${ }^{5}$. With thymic aging, which occurs in childhood, lymphatic tissue atrophies, and adipose tissue takes its place ${ }^{5}$. Adipose tissue is metabolically active, producing cytokines and adipocyte-related hormones that can regulate the development of immunocytes $^{6,7}$. Adipocytes have vitamin D receptors, and vitamin $\mathrm{D}$ can prevent differentiation of adipocytes and alter their secretion of proinflammatory cytokines and adipose-related hormones ${ }^{8,9}$.

Lack of vitamin D is a worldwide epidemic, due to insufficient intake or inadequate sunlight exposure, possibly starting before birth ${ }^{2,10}$. Forty percent to $90 \%$ of older indi- viduals do not have sufficient vitamin D levels ${ }^{2}$. Human skin can metabolize vitamin D from cholesterol in the presence of sunlight, but a man dressed only in swim trunks at latitudes in the Northern United States would have to expose himself to sunlight for at least 10 minutes every day to meet requirements ${ }^{2,11}$. Darker-skinned individuals and persons living farther north (or farther south in the Southern Hemisphere) would have to stay out in the sun longer ${ }^{11}$. Low ambient temperatures throughout certain times of the year in much of the world, cloud cover, cultural or religious norms, and risk of skin cancer might prevent many people from deriving sufficient vitamin D through this method. Vitamin $\mathrm{D}$ is also available in limited quantities in certain foods, such as milk and fish, but one would have to consume at least a 9-ounce sockeye salmon fillet daily or greater amounts of other sources to ingest enough through $\operatorname{diet}^{12}$.

The health consequences of inadequate vitamin D intake appear to be quite significant. Epidemiologic investigations have linked serum vitamin D levels to mortality, cardiovascular disease, falls, fractures, and cognitive and mental illness $^{2}$. As the prevalence of certain autoimmune diseases varies with latitude, it has been theorized that sunlight exposure, and therefore vitamin $\mathrm{D}$, may play a role in their pathogenesis ${ }^{13}$.

The etiologies of autoimmune rheumatic diseases are incompletely understood and involve genetic and environmental factors. A longstanding view is that a dysfunctional immune response to an environmental antigen targets molecularly similar autoantigens, perhaps environmentally modified, which results in autoimmune disease ${ }^{14}$. Numerous proteins found in the synovial membrane, such as fibrinogen, type II collagen, vimentin, and $\alpha$-enolase, have been considered as potential autoantigens in RA, during which, as a result of an immune-mediated inflammation, they undergo a change in arginine residues known as citrullination ${ }^{14}$. Two microbial antigens, Proteus mirabilis and Porphyromonas gingivalis, and tobacco product con-

See Prevalence of vitamin D insufficiency/deficiency in RA, page 53

Personal non-commercial use only. The Journal of Rheumatology Copyright @ 2011 . All rights reserved. 
stituents have been theorized to be environmental triggers of the immune response in $\mathrm{RA}^{14,15}$. Vitamin D might prevent or alleviate autoimmune disease, suppressing the humoral immune response and enhancing immune tolerance.

This issue of The Journal features the results of an investigation that provides important new epidemiologic evidence about the relationship between vitamin $\mathrm{D}$ and $\mathrm{RA}^{16}$. A population of 850 patients with RA was surveyed as part of a national study in veterans' hospitals across the United States. Prior studies had tried to establish a relationship, but they either used dietary vitamin D intake as a measure of sufficiency, which is a suboptimal measure, or relied upon rather small subject populations, with conflicting results ${ }^{16}$. Among the participants of the current investigation, there was an $84 \%$ prevalence of vitamin D insufficiency (serum levels $<30 \mathrm{ng} / \mathrm{ml}$ ) and patients with inadequate vitamin D levels had a higher likelihood (odds ratio 2.00; 95\% CI 1.63-2.45) of having anti-cyclic citrullinated peptide antibodies. Almost half were using vitamin D supplementation, although the dose of supplementation was not recorded. Among subjects who were not being supplemented, more severe deficiency $(<20 \mathrm{ng} / \mathrm{ml})$ was associated with symptoms: greater numbers of tender joints.

Even in the absence of autoimmune disease, it is recommended that individuals should be tested for serum vitamin D levels, and those persons whose serum vitamin D levels fall below $32 \mathrm{ng} / \mathrm{ml}$ be supplemented in the absence of renal dysfunction or nephrolithiasis ${ }^{2}$. Use of this level is based on evidence that the counterregulatory hormone to vitamin D in calcium regulation, parathyroid hormone, which declines as vitamin D levels rise, reaches its lowest concentration at vitamin D levels from 30 to $36 \mathrm{ng} / \mathrm{ml}^{2}$. For many individuals, a 2000 IU daily supplement might be sufficient, but for some, including a number of elderly persons, a higher dose will be necessary ${ }^{2}$. Doses of up to 10,000 units a day have been given, and serum levels have reached $56 \mathrm{ng} / \mathrm{ml}$ without toxicity $^{2}$. Even suboptimal vitamin D supplementation reduces falls, fractures, and systolic blood pressure, and improves balance ${ }^{2}$.

Randomized controlled trials will be necessary to establish whether correction of vitamin D insufficiency confers additional benefits in the prevention and treatment of autoimmune rheumatic diseases, such as RA. Such trials might also consider alternative theories about the role of vitamin D in autoimmunity. One theory posits that vitamin $\mathrm{D}$ insufficiency in autoimmune disease is a consequence rather than a modifier of an immune response to an antimicrobial antigen, and that treatment should include antibiotics and the addition of the angiotensin-receptor blocker olmesartan, rather than vitamin $\mathrm{D}$, to reverse antibacterial-induced alteration of the vitamin $\mathrm{D}$ receptor ${ }^{17}$.

Another question that needs to be addressed in randomized controlled trials is whether additional vitamin D supplementation to raise serum levels beyond $32 \mathrm{ng} / \mathrm{ml}$ will bet- ter prevent or treat autoimmune rheumatic disease. One recent epidemiologic investigation implied a level of 40 $\mathrm{ng} / \mathrm{ml}$ conferred a greater overall survival benefit in older persons ${ }^{18}$. In a small, uncontrolled trial in which vitamin D levels of subjects were not measured, individuals with RA consumed $2 \mu \mathrm{g}$ alfacalcidiol for 12 weeks. Participants had significantly fewer swollen joints and an improvement in 2 symptom scale scores, the Ritchie articular and Lee indices ${ }^{19}$. In another uncontrolled trial, 20 people with RA took a $1 \mu \mathrm{g}$ dose for only 2 months, but did not improve on disease symptom scale scores ${ }^{19,20}$. Further analysis of the data in epidemiologic studies such as that published in this issue of The Journal might suggest new threshold values for vitamin $\mathrm{D}$ concentrations that might be used to create new target endpoints in future prospective trials.

\section{E. PAUL CHERNIACK, $M D$,}

Geriatrics Institute,

Division of Gerontology and Geriatric Medicine, Department of Medicine,

University of Miami Miller School of Medicine, and Bruce W. Carter Veterans Affairs Medical Center, Miami, Florida, USA

Address correspondence to Dr. Cherniack;

E-mail: evan.cherniack@va.gov

\section{REFERENCES}

1. Pelajo CF, Lopez-Benitez JM, Miller LC. Vitamin D and autoimmune rheumatologic disorders. Autoimmun Rev 2010; 9:507-10.

2. Cherniack EP, Florez H, Roos BA, Troen BR, Levis S. Hypovitaminosis D in the elderly: from bone to brain. J Nutr Health Aging 2008;12:366-73.

3. Cantorna MT. Mechanisms underlying the effect of vitamin D on the immune system. Proc Nutr Soc 2010;69:286-9.

4. Cutolo M. Vitamin D and autoimmune rheumatic diseases. Rheumatology 2009;48:210-2.

5. Dorshkind K, Montecino-Rodriguez E, Signer RA. The ageing immune system: is it ever too old to become young again? Nat Rev Immunol 2009;9:57-62.

6. Galic S, Oakhill JS, Steinberg GR. Adipose tissue as an endocrine organ. Mol Cell Endocrinol 2010;316:129-39.

7. Vachharajani V, Granger DN. Adipose tissue: a motor for the inflammation associated with obesity. IUBMB Life 2009; 61:424-30.

8. Zhuang H, Lin Y, Yang G. Effects of 1,25-dihydroxyvitamin D3 on proliferation and differentiation of porcine preadipocyte in vitro. Chem Biol Interact 2007;170:114-23.

9. Menendez C, Lage M, Peino R, Baldelli R, Concheiro P, Dieguez $\mathrm{C}$, et al. Retinoic acid and vitamin $\mathrm{D}(3)$ powerfully inhibit in vitro leptin secretion by human adipose tissue. J Endocrinol 2001;170:425-31.

10. Merewood A, Mehta SD, Grossman X, Chen TC, Mathieu JS, Holick MF, et al. Widespread vitamin D deficiency in urban Massachusetts newborns and their mothers. Pediatrics 2010;125:640-7.

11. Hollis BW. Circulating 25-hydroxyvitamin D levels indicative of vitamin D sufficiency: implications for establishing a new effective dietary intake recommendation for vitamin D. J Nutr 2005; 135:317-22. 
12. U.S. Department of Agriculture. National nutrient database for standard reference, Release 22 (IU) content of selected foods per common measure, vitamin D sorted by nutrient content 2009 [Internet. Accessed 2009 December 31]. Available from: http://www.ars.usda.gov/SP2UserFiles/Place/12354500/Data/SR22/ nutrlist/sr22w324.pdf

13. Cantorna MT, Mahon BD. Mounting evidence for vitamin D as an environmental factor affecting autoimmune disease prevalence. Exp Biol Med (Maywood) 2004;229:1136-42.

14. Wegner N, Lundberg K, Kinloch A, Fisher B, Malmstrom V, Feldmann M, et al. Autoimmunity to specific citrullinated proteins gives the first clues to the etiology of rheumatoid arthritis. Immunol Rev 2010;233:34-54.

15. Ebringer A, Rashid T, Wilson C. Rheumatoid arthritis, Proteus, anti-CCP antibodies and Karl Popper. Autoimmun Rev 2010; 9:216-23.

16. Kerr GS, Sabahi I, Richards JS, Caplan L, Cannon GW, Reimold A, et al. Prevalence of vitamin D insufficiency/deficiency in rheumatoid arthritis and associations with disease severity and activity. J Rheumatol 2011;38:53-9.

17. Waterhouse JC, Perez TH, Albert PJ. Reversing bacteria-induced vitamin D receptor dysfunction is key to autoimmune disease. Ann NY Acad Sci 2009;1173:757-65.

18. Ginde AA, Scragg R, Schwartz RS, Camargo CA Jr. Prospective study of serum 25-hydroxyvitamin D level, cardiovascular disease mortality, and all-cause mortality in older US adults. J Am Geriatr Soc 2009;57:1595-603.

19. Andjelkovic Z, Vojinovic J, Pejnovic N, Popovic M, Dujic A, Mitrovic D, et al. Disease modifying and immunomodulatory effects of high dose 1 alpha $(\mathrm{OH})$ D3 in rheumatoid arthritis patients. Clin Exp Rheumatol 1999;17:453-6.

20. Hein G, Oelzner P. Vitamin D metabolites in rheumatoid arthritis: findings - hypotheses - consequences [German]. Z Rheumatol 2000;59 Suppl 1:28-32.

J Rheumatol 2011;38:5-7; doi:10.3899/jrheum.100792 